\title{
Evaluation of influence of the logistics chain infrastructure on the logistics costs formation
}

\author{
Andrii Galkin ${ }^{1 *}$, Yevhen Kush ${ }^{1}$ and Nataliia Davidich ${ }^{2}$, Yuriy Davidich ${ }^{3}$ \\ ${ }^{1}$ O. M. Beketov National University of Urban Economy in Kharkiv, department of transport systems \\ and logistics, (Kharkiv) \\ ${ }^{2}$ O. M. Beketov National University of Urban Economy in Kharkiv, department of project management \\ in municipal services and construction \\ ${ }^{3}$ Ukrainian State University of Railway Transport, department of transport systems and logistics \\ (Kharkiv)
}

\begin{abstract}
The article is devoted to revealing the influence of the infrastructure of logistics chain on expenses in it. Possible types of warehouses which can be used in the logistics chain were identified. The expenses on the functioning of the warehouse according to its parameters were analyzed. The variable costs estimation of the warehouse was modelled via the freight turnover. The fixed costs estimation of the warehouse was modelled via its area. Regression nonlinear models of variables and fixed expenses of own/hired warehouse were obtained.
\end{abstract}

\section{Introduction}

The problem of adjusting the process of continuous supply of goods to a retail network requires the solution of the problem of the infrastructure of the logistics chain [1]. The easiest solution for retailers is the option when the goods are delivered to the stores "directly", the control over the volume of stocks belongs to the management company on the outsourcing rights [2] or "fulfilment" [3]. According to the results of research [4], most suppliers are not able to provide such services, or the expenses of these services are too high. An analysis of the modern logistics market in Ukraine shows that not more than $15 \%$ of suppliers can fulfill their contractual obligations when delivering goods. With the increase of sunstainable freight turnover, the question of having of own warehouse arises. Many experts and researchers agree with the idea of combined flows via a company-owned distribution center or warehouse, which can accumulate the required margins and reduce overal costs [5], that is, to introduce additional participants into the infrastructure of the logistics system.

On the other hand, as a result of falling purchasing power of end-consumers, retailers began to reduce the size of orders to decrease stock level. This fact has a negative effect both on the logistics chain infrastructure and in general on its key performance indicators, which leads to the need to find alternative ways to reduce their own costs to ensure product competitiveness and sales. The set of elements that perform logistic tasks and ensure the

\footnotetext{
* Corresponding author: galkin.tsl@gmail.com
} 
implementation of logistics processes determine its infrastructure and affect the formation of logistics expenses.

\section{Literature Survey and Purpose Statement}

Analysis of studies has shown that in the field of logistics services, there are two options for using the warehouse in the distribution of material flows [5]:

1) construction or rental of premises and the creation of a warehouse at their base;

2) use of public warehouses or outsourcing.

According to researchers [7], warehouses by the form of use can be classified as follows (Fig. 1):

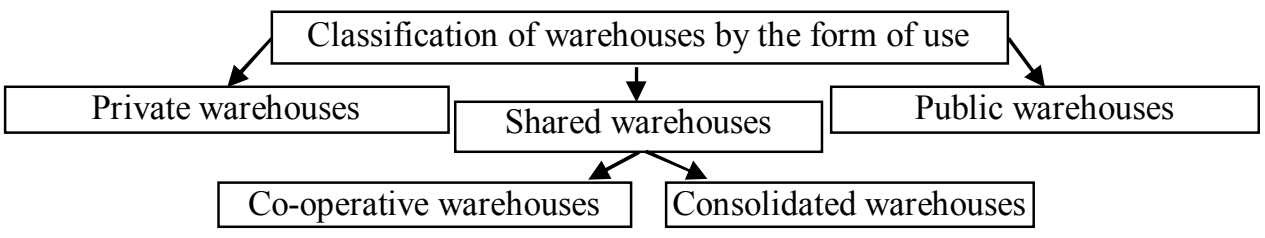

Fig. 1. Classification of warehouses by the form of use.

The authors in [2] propose to allocate two types of warehouses: co-operative warehouses and Public warehouses. The various types of warehouses by the form of use have a number of advantages and disadvantages [4]. The Company-owned warehouse has a fairly large number of benefits, but in terms of profitability, not every enterprise has the ability to hold it.

In the case of using an own warehouse, the costs of its operation consist of lease, wage costs, operating costs, utilities, depreciation, etc. [6]. The value of the processing of goods in the hired warehouse is influenced by the type of goods (their weight, volume, consistency) [8], the type of handler [9], the type of equipment for storing goods taking into consideration their properties [10], the technology of placement and stowage of goods during storage and processing [6]. Recently, "secure storage" of goods and equipment has become common. Secure storage of goods implies a basic list of operations, such as unloading and loading, receiving goods, picking and controlling orders, marking, repacking and other services.

The type of elements of the logistics infrastructure determines the costs necessary to deliver the material flow to the end-conusmer. The costs of the functioning of the warehouse scientists propose to determine on variable and fixed components [6]. Variables include manipulation costs (internal displacement costs) and costs that vary depending on the size of stocks and the level of material flow $[6,12]$. Fixed costs include costs that do not depend on stocks level. These include leasehold depreciation, depreciation of equipment, salaries of managerial staff and specialists, utility bills and other $[6,12,13]$.

Thus, the total costs of functioning of the warehouse can be determined by the following dependence[14]:

$$
C_{w}^{o}=C_{f} S+C_{\mathrm{var}} Q
$$

where $C_{f}$ - fixed costs, money units/day; $S$ - area of the warehouse, $\mathrm{m}^{2} ; C_{\text {var }}$ - variable costs, money units $/ \mathrm{m}^{2} ; Q$ - freight turnover of the warehouse, $\mathrm{t} /$ day.

The expenses for the operation of the hired warehouse will be equal to:

$$
C_{w}^{r}=T \cdot Q,
$$

where $T$ - fare for storage (processing) of one ton of material flow, c.u /t. 
Provided that the manufacturer's costs for warehouse operations are known, the retail network has been formed and the maintenance costs for the material flow are fixed, the choice of the type of intermediate warehouse can determine the costs of the logistics system. The purpose of the article is to investigate the influence of the logistics chain infrastructure on the formation of logistics costs.

\section{Methodology of conducting experimental researches}

The infrastructure of the logistics system can be represented as a set of $M$ producers of material flow, $W$ of warehouses and $S$ of retailers. The connection between the elements of the logistics system participants is carried out by means of transport on the site of the Manufacturer-Distribution and Distribution-Sales (Figure 2).

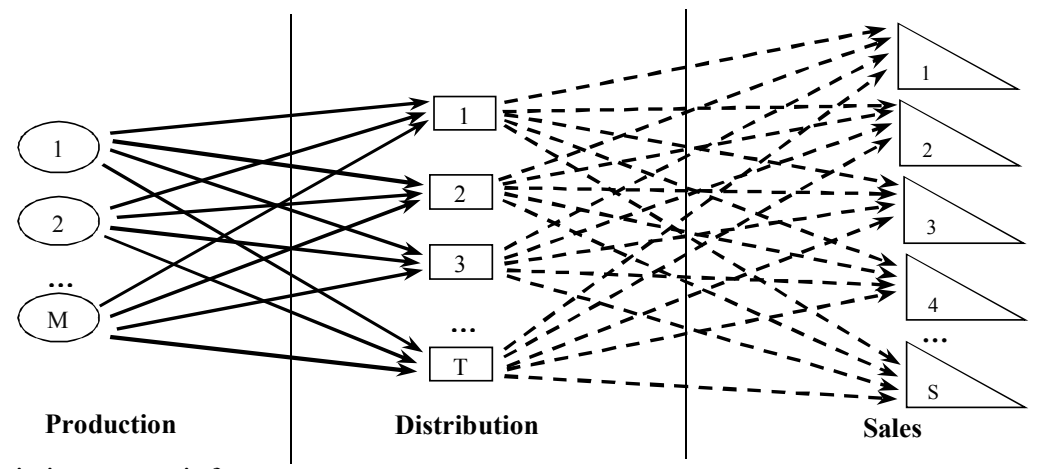

Fig. 2. Logistics system infrastructure:

$\longrightarrow$ - the movement of material flow from the sphere of production into the distribution sector;

$---\rightarrow$ - the movement of material flow from the sphere of distribution into the sphere of sales.

In this case, the total logistics costs for the promotion of the material flow in the logistics system will be equal to:

$$
C_{L S}=\sum_{i=1}^{n} C_{i}
$$

where $C_{i}$ expenses of the $i$-th participant of the logistics system, money units;

$n$-number of participants in logistics system, units.

In expanded form, the total logistics costs for the promotion of the material flow can be formalized as follows:

$$
C_{L S}=\sum_{j=1}^{M} C_{j}^{M}+\sum_{k=1}^{T} C_{k}^{M-W}+\sum_{l=1}^{W} C_{l}^{W}+\sum_{m=1}^{D} C_{m}^{W-S}+\sum_{o=1}^{S} C_{o}^{S},
$$

where $C_{i}^{M}$ - expenses for storage of material flow in the warehouse of $j$-th manufacturer, money units; $M$ - number of producers, units; $C_{k}^{M-W}$ - expenses for transportation of material flow from the sphere of production in the sphere of distribution by $k$-th transport participant, money units; $T$ - number of transport participants in the section Production-Distribution, units; $C_{l}^{W}$ - the cost of storing the material flow in the $l$ warehouse, money units; $W$ - number of warehouses, units; $C_{m}^{W-S}$ - expenses for the transportation of material flow from the sphere of distribution into the sphere of marketing by $m$-th transport participant, money units; $D$ - the number of transport participants in the Distribution-Sales section, units; $C_{n}^{S}-$ the cost of storing the material flow of the $o$-th participant of the retail network, money units; $S$ - number of participants in retail network, units. 
The formation of the costs of the logistics chain for the material flow movment depends on the type of warehouse used in the system. In addition to the own and hired warehouse, the company may be offered to use a shared warehouse. The costs of using the shared warehouse include only the cost of renting the warehouse, depending on the area chosen and the location of the warehouse. They may depend on the size of the chosen area and location.

Research of the dependence of variable and fixed costs on its parameters was carried out using regression and correlation analysis [15]. Characteristics of model parameters were determined using methods of mathematical statistics, and the significance of model factors was determined on the basis of Student's t-test, information capacity of models - using F-ratio. The tightness of the relationship between dependent and independent variables was determined using the correlation coefficient and the approximation error. Further, a study was conducted of the dependence of the variable costs of own warehouse on the volume of storage of products using nonlinear regression analysis. A graphical representation of this dependence is shown in Fig. 3.

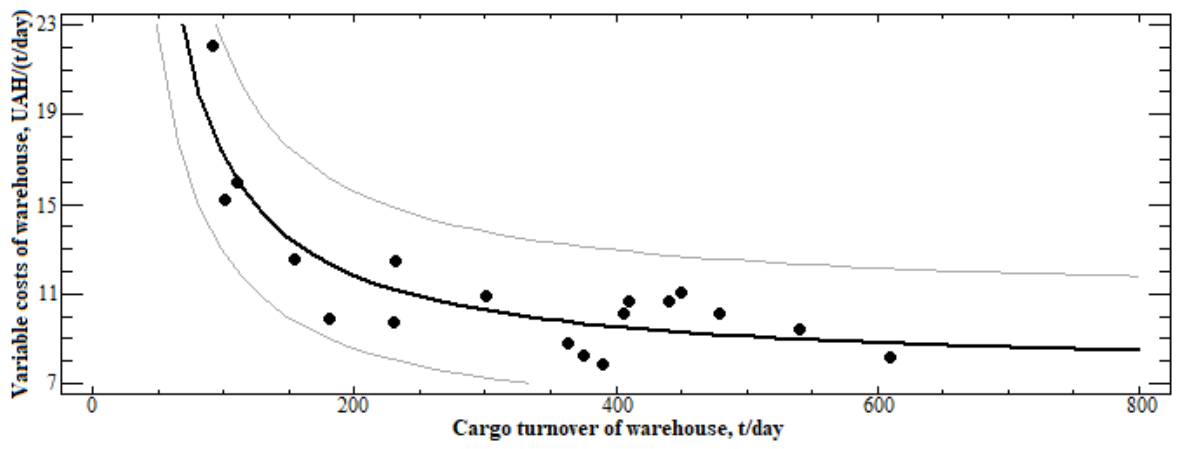

Fig. 3. Chart of variable expenses dependence in owned warehouse on its freight turnover.

Mathematically, this dependence can be described by a regressive nonlinear model:

$$
C_{\mathrm{var}}=\left(2,7343+\frac{140,792}{Q}\right)^{2}
$$

where $Q$ - freight turnover of warehouse, $\mathrm{t} /$ day.

Statistical characteristics of the obtained model (correlation coefficient 0.77, F-ratio 53.31) testify to its adequacy. An increasing of the freight turnover in the warehouse leads to the use more handling machines and workers to meet the demand, and vice verse. Subsequently, a study was made of the fixed costs estimation of owned warehouse on the warehouse space $(S)$ variation, fig 4.

Mathematically, this dependence can be described by a regressive nonlinear model:

$$
C_{f i x}=20,5336+\frac{10406}{S} \text {. }
$$

Statistical parameters for the models obtained (correlation coefficient 0.92, F-ratio 190.99) testify to its adequacy.

With the increase in warehouse space the cost of its maintenance and wages and utilities also increases. However, at the same time, the specific cost of operatting $1 \mathrm{~m}^{2}$ of warehouse space is reduced, which leads to a reduction in fixed costs.

Consequently, the cost of storing the material flow in the l-man will be equal to:

$$
C_{l}^{W}=\sum_{l=1}^{W} Q_{l} \cdot\left(2,7343+\frac{140,792}{Q_{l}}\right)^{2}+\sum_{l=1}^{W} S_{l} \cdot 20,5336+\frac{10406}{S_{l}} .
$$




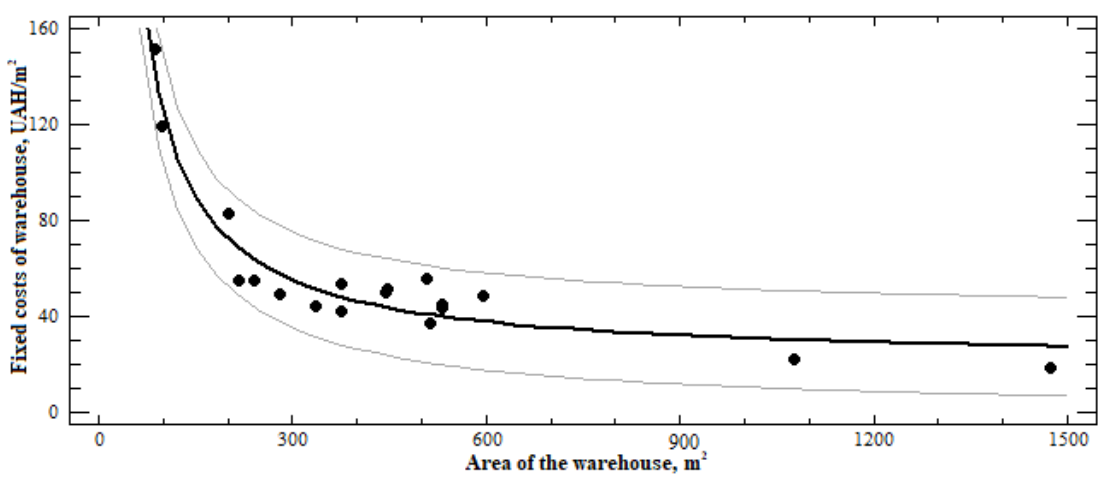

Fig. 4. Dependence of fixed expenses of own warehouse on its area.

The technological process of material flow processing at the hired warehouse is a set of consistently executed operations that are provided to the customer as services. These services are related to preparation for acceptance of products, receipt, transfer, unpacking, acceptance of products by quantity and quality, placing on storage, packing, selection, complectation, preparation for a delivery and delivery of products to the consumer. The effectiveness of managing processes in the warehouse essentially depends on the execution of separate operations [11]. The costs for technological performance of the warehouse can be found as the sum of the component costs of operations performed in it:

$$
C_{T}^{W}-{ }^{R}=C_{s t}^{W}+C_{u}^{W}+C_{l}^{W}+C_{c}^{W}+C_{p}^{W}+C_{o}^{W}
$$

where $C_{\mathrm{st}}^{W}$ - the storage expenses of 1 ton of goods, $\mathrm{UAH} /(\mathrm{t} /$ day $) ; C_{u}^{W}-$ the unloading expenses 1 ton of product, $\mathrm{UAH} /(\mathrm{t} / \mathrm{day}) ; C_{l}^{W}$ - loading expenses 1 ton of product, $\mathrm{UAH} /\left(\mathrm{t} /\right.$ day); $\quad C_{c}^{W}$ - the complectation expenses of 1 ton of goods, $\mathrm{UAH} /(\mathrm{t} /$ day); $C_{n}^{W}$ - packing expenses 1 ton of goods, $\mathrm{UAH} /(\mathrm{t} / \mathrm{day}) ; C_{n}^{W}$ - other expenses assossiated with technology of freight processing, $\mathrm{UAH} /(\mathrm{t} /$ day $)$.

The main indicator for estimation the warehouse efficiency is the freight turnover, which depends on the parameters of the technological operation, namely: the processing time of one order, the working shift, the efficiency of the use of equipment and other parameters:

$$
Q=f\left(M_{1}, M_{2}, \ldots, M_{n}\right),
$$

where $M_{l}, M_{l}, \ldots, M_{n}$-parameters of technological operations in the warehouse.

Fig. 5 shows the dependence of the total costsc of servicing $1 \mathrm{t}$ of material flow, depending on the area of the warehouse.

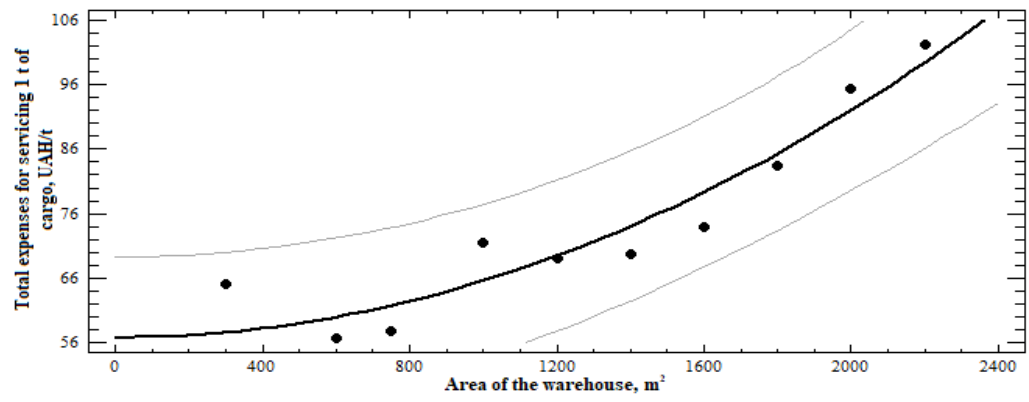

Fig. 5. The dependence of the total costs per 1 ton of MF depending on the area of the warehouse. 
There is a feedback between the parameters of technological operations in the warehouse, which are dependent on freight turnover.

Within the presented research, an option was considered when the company selects to use of hired warehouse. In this case, it pays only the cost of services, which includes all the costs, as well as the use of the infrastructure of the complex.

Mathematically, this dependence can be described by a regressive nonlinear model:

$$
C_{T}^{W_{-}{ }^{R}}=56,76+8,83 \cdot 10^{-6} \cdot S^{2} .
$$

Statistical parameters for the models obtained (correlation coefficient 0.91, F-ratio 79.53) testify to its adequacy. On the basis of the obtained dependence it can be concluded that with the increase of the warehouse area, the cost of services will increase.

\section{Conclusions}

The study of the influence of the logistics chain infrastructure on the formation of logistics costs in the article enabled to formulate the following conclusions:

- it was established that the infrastructure of the logistic chain (the types of warehouses), determines the logistics costs for the process of material flow progression;

- it was established that the total cost of storing depends on the volume of goods stored on it and the area of the warehouse. It is possible to formalize the total costs using a regressive multifactor model, in which the variables included the goods turnover in the warehouse and its area.

The results obtained in the article allow to determine the costs of functioning of the warehouse, depending on its type. This allows us to determine the total logistics costs, which consist of the costs of storage, transportation and distribution, which the system spends on promoting the methionic flow in it.

\section{References}

1. J. Fernie, Handbook of Logistics and Supply-Chain Management, (2008)

2. A. Galkin, C. Dolia, N. Davidich, TRP, 27, 1187-1194 (2017)

3. G. Vaidyanathan, CACM, 48, 89-94 (2005)

4. I. Litomin, I. Tolmachov, A. Galkin, TCP, 16, 313-322, (2016)

5. R. D. Shapiro, J. L. Heskett Logistics Strategy: cases and concepts, (1985)

6. E. V. Krikavskiy, LogIstika dlya ekonomIstIv, (2014)

7. A. G. Kalchenko, LogIstika, (2003)

8. V. M. Kisliy, O. A. Bilovodska, O. M. Olefirenko, O. M. Smolyanik, Logistika: Teoriya ta praktika, (2010)

9. L. Douglas, M. Cooper, J. Pagh, IJLM, 9, 1-19 (1998)

10. L. Filina-Dawidowicz, M. Postan, LF, 12 (2016)

11. A. Razzaque, C. Sheng, IJPDLM, 2, 89-107, (1998)

12. M. Asadabadi, IJIEC, 6, 305-314, (2015)

13. R. H. Wilson, HBR, 13, 116-128, (1943)

14. Y. Kush, V. Skrypin, A. Galkin, K. Dolia, I. Tkachenko, N. Davidich, TRP, 30, 216-225 (2018)

15. A. Frenkel, Mnogofaktornyie korrelyatsionnyie modeli proizvoditelnosti truda, (1966) 